\title{
Exploring Adaptations and Successful
}

Implementation of Traditional Healers as Adherence Partners for People Living with HIV in Rural Mozambique: A Qualitative Assessment

Carolyn M Audet ( $\square$ carolyn.m.audet@vanderbilt.edu )

Vanderbilt University Medical Center https://orcid.org/0000-0002-4715-1346

Mariah Pettapiece-Phillips

Vanderbilt University Medical Center

Jose Salato

Friends in Global Health

\section{Research}

Keywords: HIV/AIDS, fidelity to EBP, adaptations to EBP, traditional medicine, adherence to medication, community-based interventions

Posted Date: August 27th, 2020

DOI: https://doi.org/10.21203/rs.3.rs-63991/v1

License: (c) (i) This work is licensed under a Creative Commons Attribution 4.0 International License.

Read Full License 


\section{Abstract}

Background: Implementing evidence-based interventions to improve adherence to antiretroviral therapy (ART) is essential to controlling the HIV epidemic in sub-Saharan Africa. Evidence-based community health worker interventions address barriers to medication retention by shifting the task from overburdened health facilities and emphasizing a more patient-centered approach in a comfortable location.

Methods: We employed traditional healers to implement an evidence-based community health worker program for people living with HIV (PLHIV) in rural Mozambique. Participants received support services for 2 months after their first positive test. Healers were trained to provide counseling, HIV education, support with disclosure, and advocacy at the health unit. We interviewed 23 PLHIV and conducted focus groups with 19 traditional healers to explore implementation fidelity and identify unplanned adaptations made during the program.

Results: Healers and PLHIV report counseling, HIV education sessions, and support with disclosure were largely delivered with fidelity. Due to the extreme poverty in the region, healers reported the need to add additional messages to support people who needed to take medication but had no food to mitigate the side effects. Patient advocacy at the health center proved difficult to implement. Negative attitudes towards PLHIV and traditional healers led to participants reporting extremely poor treatment by health care providers; the lack of respect made it difficult for healers to assist PLHIV with issues like long wait times, lost patient identification cards, or enduring medication side effects. Healers adopted directly observed therapy as an unplanned strategy to support non-adherent PLHIV.

Conclusion: Given low levels of literacy and substantially different views on disease causation, healers delivered most core components of the intervention with fidelity. Healers attempted to implement the patient advocacy component but resistance from health care providers proved challenging. Future efforts will need to develop more effective strategies to overcome negative healer-clinician dynamic.

Clinical Trials Registry: Name of the registry: Traditional Healers as Adherence Partners for Persons Living with HIV in Rural Mozambique (PLHIV). Trial registration number: NCT03076359. Date of registration: $3 / 6 / 2017$, retrospectively registered. URL of trial registry record: https://clinicaltrials.gov/ct2/show/NCT03076359?cond=Hiv\&cntry=MZ\&draw=2\&rank=7

\section{Contributions To The Literature}

- Traditional healers are an untapped resource to provide community-based support to people living with HIV. We used the ADAPT-ITT framework to adapt a community health worker training for use by traditional healers but questions about healer ability to implement the strategies with fidelity remained.

- Trained traditional healers provided counseling and educational support with fidelity to those newly diagnosed with HIV. Frustrated by perceived deception about medication adherence by their clients, 
$40 \%$ of healers adapted the intervention to include directly observed therapy. Directly observed therapy was considered acceptable and appropriate to the people living with HIV and was undertaken by healers without expectation of additional compensation.

- Health care workers, while involved in the adaptation of the project, consistently ignored attempts by healers to advocate for their patients' health and well-being. Thinly vailed disregard for traditional healers, coupled with frustration with patients who need additional support from the health system, made it difficult for healers to advocate for patients.

\section{Introduction}

Implementing evidence-based interventions to improve adherence to antiretroviral therapy (ART) is essential to controlling the HIV epidemic in sub-Saharan Africa. ART, when taken regularly, effectively suppresses HIV viral replication among persons living with HIV (PLHIV). ${ }^{1-4}$ People with delayed, disrupted or discontinued ART experience rapid disease progression, develop resistance to ART, and remain more likely to transmit the virus during sexual activity. ${ }^{5-7}$ Though widespread implementation of "test and treat" in 2016 has improved global ART coverage ${ }^{8-10}$ poor adherence and treatment interruptions are common, particularly in resource-limited settings where poorly-functioning health systems (medication stock outs, lack of trained providers), ${ }^{11-13}$ sociocultural norms and beliefs (HIV stigma, mistrust in health system), ${ }^{11,12,14-22}$ economic constraints (food insecurity, lack of transportation), ${ }^{13,17,22-25}$ as well as family and individual barriers (HIV knowledge, preference for traditional medicine) $)^{17,18,23,25,26}$ undermine access and willingness to remain in treatment.

Evidence-based interventions address barriers to medication retention by shifting the task from overburdened health facilities to community health workers for ART provision and education and emphasizing a more patient-centered approach via community ART distribution points, ${ }^{27,28}$ adherence clubs, ${ }^{28-32}$ home-based and spaced refill visits, ${ }^{33,34}$ and employing community health workers (CHWs) for ART provision and education. ${ }^{35-38}$ When implemented with fidelity, CHW programs have shown to increase patient adherence to ART, leading to improved viral suppression. ${ }^{39}$ In rural Mozambique, CHWs have struggled to effectively implement interventions due to a lack of transport (to conduct home visits), insufficient and irregular training programs, poor integration to the clinical system, the frequent turnover among volunteer staff $37,38,40$ and low levels of patient trust. Engaging traditional healers to perform these tasks allows us to overcome many of the logistical issues, given that healers live in the same communities as their patients, are trusted members of the community, and rarely stop practicing traditional medicine.

To capitalize on these existing community-based health providers in Mozambique, we adapted a CHW intervention for implementation by traditional healers. Across rural SSA, people living with HIV commonly seek out treatment from traditional healers. ${ }^{41}$ Healers provide care that is socially acceptable, are wellrespected, and already have an existing relationship with people in their community. ${ }^{21,42}$ Moreover, healers have been shown to influence patients' attitudes and behaviors towards HIV care 
utilization. ${ }^{22,43-45}$ Thus, our intervention aimed to leverage this established relationship by training healers as treatment partners to promote and facilitate ART uptake and maintenance.

Were healers capable of delivering the intervention with fidelity? Many of the traditional healers engaged as treatment supporters had low levels of literacy and limited experience working with the health system. While we have employed the ADAPT-ITT framework to ensure pre-implementation acceptability, appropriateness and feasibility among healers, people living with HIV, and clinicians, we believed it necessary to determine if they could deliver the core components of the intervention with fidelity. Interventions delivered with diminished fidelity may fail to produce the desired outcomes. ${ }^{46}$ Specifically, we focused on understanding ways the intervention was adapted and tailored by healers during implementation and aspects of the intervention that did not function as intended. Here, we report on qualitative interviews with healers and patients who participated in the program.

\section{Methods}

\section{Study Location}

Zambézia province is in north-central Mozambique. Zambézia is home to 5.1 million people and is one of the poorest regions in the world. Only $51 \%$ of adults over 15 are literate. ${ }^{47,48}$ The adult HIV prevalence was $15 \%$ in 2015 , one of the highest in sub-Saharan Africa (SSA). ${ }^{49,50}$ Health facilities are governmentrun, and consultations are provided nearly free of charge (a token fee of one Meticais [one US cent] is charged for some services). HIV testing and medication for chronic diseases such as anti-retroviral therapy (ART) medications are provided at no cost to patients. The Mozambique Ministry of Health (MISAU) has adopted patient-centered ART delivery models ${ }^{51}$ designed to reduce transportation costs and time waiting at the health facility, increase social support from family and friends, and provide counseling to someone who recently missed an appointment or medication pick up. Despite the provision of evidence-based clinical and community interventions, only $71 \%$ of patients remain engaged (defined as one medication pick-up within the past 59 days) one year after enrollment in 2019. ${ }^{52}$ However, when applying more conservative definitions (e.g. medication possession ratio), estimated adherence to medication is substantially lower. ${ }^{30,53}$

\section{Study Population}

One hundred and thirty-one patients agreed to receive support from a traditional healer after their initial positive test (from 138 eligible patients approached). To select their healer, patients were provided a list (with photos) of trained healers living in their communities. Fifteen participants died before the end of the study and 12 out-migrated from the study district. We used purposeful sampling to select 30 individuals, with a focus on identifying people with varying levels of medication adherence and those who live both near and far from the health facility. We recruited 23 of those selected (three were traveling outside of the 
district and four were not found despite three attempts to locate them); all who were approached agreed to complete an in-depth interview.

Forty-four traditional healers volunteered to provide support to patients. Two did not complete the training and of the remaining 42 , only 26 of these were selected by patients. We reached out to 24 traditional healers who provided patient support ( 2 died during the study); 19 participated in one of 2 group sessions. Among the 5 healers who did not participate, 3 were working and 2 were traveling at the time of our interviews.

\section{Intervention Protocol}

The evidence-based intervention was based on the Adherence Support Worker program ${ }^{53}$ created in Malawi. The essential "core" components of the intervention include (1) education about HIV medication side effects and strategies for overcoming them, (2) counseling to understand barriers to medication adherence and the co-creation of strategies to overcome these challenges, (3) Facilitation of HIV status disclosure to family members, and (4) Advocacy of patient needs/concerns to health care providers. The evidence-based intervention was originally designed for use by community health workers. The program was tailored for use by traditional healers using the ADAPT-ITT framework ${ }^{54}$ in $2017,{ }^{43}$ and to allow for patients to select the healer of their choice. Traditional healers who were selected for the program were given two weeks of counseling and clinical training, six hours of contact time with local health care providers to facilitate relationship building, and a structural change at the health system that allowed healers to "jump the queue" with their patients.

\section{Ethics, Consent, and Permissions}

This study was approved by the Vanderbilt University Institutional Review Board (IRB\# 150217) and the Zambézia Committee of Bioethics for Health (IRB\# 03/DIBS-Z/15). All participants provided written informed consent in their preferred language.

\section{Data Collection}

The Consolidated Criteria for Reporting Qualitative Studies guides our reporting of qualitative data collection, analysis, and findings. ${ }^{55}$ Between July and September 2019, we conducted qualitative research in the region conducted 23 semi-structured in-depth interviews at the homes of participants and 2 focus groups at a community engagement office in Namacurra District, Mozambique. The in-depth interview guide was informed by the Consolidated Framework of Implementation Research and employed open-ended questions which were asked of all participants in the same order in each interview. Questions were focused on gaining insight into a participant's experience with study activities, type, timing, and frequency of services provided, and the perceived quality of the healer support. We also elicited 
suggestions for program improvement. The focus group guide for traditional healers consisted entirely of open-ended questions, designed to gain insights into the fidelity of delivering study activities, barriers to patient support, modifications that were implemented "on the fly" during the study, activities that were perceived as most successful, and suggestions for program improvement.

Two trained qualitative fieldworkers and the study PI conducted one-on-one interviews and focus groups in Portuguese and Echuabo. These interviewers have received training in qualitative methods while working with several $\mathrm{NIH}$-funded research projects over the past 12 years. The in-depth interview participants had not previously met the interviewers. The traditional healers had previously met the interviewers during a baseline survey in 2017. Interviews were conducted at the home (or preferred location) of each patient while focus groups took place at a community field office for community health support from the local non-governmental organization, Friends in Global Health. Field notes were taken during the interviews and focus groups; after each interview, the team would meet to discuss each session to determine if we were reaching data saturation and what additional questions we still had. After being audio-recorded, interviews were transcribed in either Echuabo or Portuguese. Interviews in Echuabo were subsequently translated to Portuguese. Each transcription and translation were cross-referenced to ensure quality. All Portuguese transcriptions were subsequently translated to English by a professional, certified translator. Duration of participant interviews averaged 26 minutes. Healer focus groups averaged 3 hours and 20 minutes.

\section{Analysis plan}

English and Portuguese transcripts were reviewed by CMA upon their completion. Two researchers (MPP and CMA) conducted a reflexive thematic analysis using MAXQDA $2020 \odot$ software. ${ }^{56}$ Previous research detailing patient barriers to ART retention and adherence, challenges implementing community-based ART support services for people living with HIV, along with the information-motivation-behavior theory guided deductive code development, ${ }^{57-59}$ while in-vivo (inductive) codes were generated when participants reported unique challenges to selecting a treatment supporter, ART adherence, or novel strategies used to support participants. Traditional healer focus groups were conducted first, and patient interviews were used as an opportunity to check comments and concerns raised by the healers. MPP and CMA met to develop, define, and compare application of codes to the transcribed interviews; after which, there was complete agreement of deductive and inductive codes and sub-codes to the 23 interviews and 2 focus groups.

\section{Results}

Twenty-three patients and 19 healers participated in our post-intervention interviews. Among our 23 patient participants, 12 were women (52\%) with a median age of 35 years (women: 28 years, men 28 years). Healer participants were primarily male $(n=14 ; 74 \%)$ with a median age of 50 years (women: 51 years, men 50 years). All our patient participants were actively engaged in HIV care, although several had 
gaps in medication pick up during the past year. Healers who participated in our focus group supported a minimum of four participants (range: $4-11$ ) during the past year.

\section{Adherence to the protocol: Did patients receive the support healers were trained to provide?}

\section{Education about medication side effects}

Healers were trained to provide psychosocial counseling, HIV education, and disclosure support to people living with HIV in efforts to increase adherence to treatment. The most common barrier to ART adherence reported by patients was medication side effects (all but one participant reported this issue). All participants reported experiencing a combination of nausea, vertigo, diarrhea, headaches and extreme hunger. One patient explained,

I was really bad! I was dizzy for one week. Then the dizziness went away and I started having diarrhea. After the diarrhea I had strong headaches. This all happened at the beginning when I started medicating! I was almost not taking it anymore. But my traditional healer came to talk to me about not stopping, that everything I was feeling would go away. And it indeed went away and now I have no reactions. (woman, 38 years)

As trained, healers provided reassurance that the side effects would lessen in time and recommended taking medication with food, however, side effects were made worse due to widespread poverty in the region, where people frequently eat only one meal per day. Healers felt an obligation to provide support for those who did not have enough food to take with their daily medication. One healer noted the conflict patients face: "Really, the difficulty that patients face is in feeding. They say, 'for me, all the advice you give us, we are fulfilling. But we have no food. When I take it without eating, I can't walk or get out of bed."' (Traditional Healer, man, 28 years old)

Healers feel a responsibility to help, but they are also living in poverty and have little to offer. They subsequently had to adapt their solutions due to a lack of available resources. One healer highlighted this conflict,

The difficulties are the same: food is the main factor for people, each patient has their own reaction, tiredness, allergies, vomiting, nausea, drowsiness, diarrhea and more. And they stay at home without being able to do any activity and so they end up having nothing to eat. That's when we are sorry, and we end up taking what little we have to help them. (traditional Healer, man, 27 years old)

Those patients who needed a long-term solution to deal with taking medication without food were told by healers to drink two cups of water (with or without sweet potato leaves) with their pills to reduce the side effects. We did not provide these recommendations; they learned these strategies from speaking with 
other patients and adapted their work accordingly. Seventy-five percent of our patients reported having to employ this strategy because they were too poor to purchase food on a daily basis.

\section{Psychosocial counseling}

Healers were trained to provide basic counseling to individuals and couples. Largely, healers felt equipped to provide these services to their patients and felt proud when their patients overcame challenges. Ten patients highlighted the emotional support they received from their healer as a key factor in their remaining on treatment. None reported experiencing poor quality counseling. One patient noted that

...this program helps people living with HIV to overcome the trauma that they go through after receiving the HIV test result. And at the beginning of the HIV treatment, when the person gets tested and the result is positive, the person gets desperate thinking that her life is over. But when they have the support [of someone] accompanying them, that person starts to feel better, excited to receive advice and realizes that there is more of a chance to live. (woman, 32 years old)

However, healers reported encountering situations they were not equipped to address. While healers were taught counseling strategies to assist in disclosure, there were many aspects of the process that were outside of their control. One described a situation with her patient,

"...whose husband abandoned her, she went to her mother's house, and the mother also kicked her out, saying she should look for who gave her this disease. She went into despair, not wanting to live, she didn't want to take the medication because she had nothing to eat. I had to feed her every day. I was sorry for her situation." (healer, woman, 51 years old)

Healers encountered these difficult situations most frequently when a patient's family was not supportive. Social support systems, including access to food or housing support are essentially non-existent in this region of Mozambique, leaving individuals to manage (or fail) on their own. Most patients interviewed reported disclosing on their own, but eight traditional healers spoke about assisting at least one patient disclose their HIV status to a family member. One healer explained his support,

I had a patient who, after taking the test, and the result was HIV+ was scared. He lived with his brother and was full of fear of revealing about his health to his brother. He didn't know what the brother's reaction would be when he learned he was HIV+. He wanted to speak, but he didn't know how he was going to do it. At the same time, fear consumed him inside, because he had to go to the hospital every month, as it should be. What if the brother asked him what he was going to do in the hospital every month? He came to talk to me; we went to the brother's house together and explained everything. Thanks to God we had no problems. (traditional healer, man, 50 years)

All participants noted how difficult it would be to take medication without the support of those closest to them. While the healer could help bridge that divide, family members who did not agree with the HIV diagnosis complicated patient efforts to adhere to medication. 


\section{The adoption of directly observed therapy}

Healers reported difficulty in supporting patients believed to be deceptive about ART adherence. In their efforts to address this, and in addition to psychosocial support and advice, healers initiated directly observed therapy (DOT) among patients suspected to be non-adherent, despite this not being taught during training. Borne from a combination of frustration with their patients and experience observing DOT use with tuberculosis patients, healers decided that, in many cases, counseling was insufficient. One patient recounted her experience with her healer.

Every time [the healer] comes over, she says that I shouldn't stop taking [my pills], not fail one day and not miss consultations. And there is more! Sometimes she asks me for the bottle to check if I'm taking it, she counts my pills, controls my pick-up day to see if I didn't fail, she does a lot for us. (man, 25 years old)

\section{One healer described how she managed particularly difficult patients.}

I had a patient who had difficulty taking it [ART]. When it came time to take it, she took the pill out of the bottle and buried it on the floor inside the house... I started going to her house every day to give her the pills. I'd put it in her mouth, give her water, check her mouth if she'd swallowed it, stayed for a few minutes then I'd leave. I did it for (2) months and I was the one who kept the pills in my house...and thank God she is now very well and thanked me every day when we see each other. She always tells me, "if it weren't for your persistence I would have died already." (traditional healer, woman, 57 years old)

The use of DOT as a strategy when healers perceived their patients to be deceitful requires additional time and effort, but none of the healers expressed irritation with performing this service. Among patients who experienced this level of observation and control, none complained.

\section{Did health care providers collaborate well with traditional healers?}

While traditional healers endeavored to adapt the protocol to assist their patients, the collaboration between healers and health care providers was less successful, often resulting in insurmountable barriers to the advocacy core component of program implementation. Both patients and healers reported experiences with health care providers that were contrary to Ministry of Health guidelines and the healer collaboration protocol. One healer explained

For some time now, there are days that we are well attended. But at the beginning of the program, we were very ashamed with the patients... The patient would take three days to be seen... The patient said, "why do you send me to the hospital with this crappy paper [referral form from the healer], which is useless? Is it possible for me to go three days without being seen?" I wore my [project] t-shirt, said let's go together, we arrived at the hospital, they did the same thing to us. They looked at me as if I was [a] 
nobody. It was too much, I was upset, the patient too, we almost gave up on this job. We were told that after dealing with our roots, playing drums and then seeing that the patient is not better, then take them to the hospital. Now what is the problem with nurses? This part we didn't understand the health professionals' reasons. But now it has improved a lot. I won't say that they always treat us well. There is still one or another that treat us well. There is still one or another that looks at us with contempt and leaves us sitting all day. (healer, male 50 years old)

The poor treatment experienced by healers and their patients undermined the hard work healers were undertaking in the community, which led to confusion and frustration. One healer noted, "When we stop to think about it, we see that health professionals are not happy with our presence around them. I think they should be happy because we are saving lives just like them." (healer, woman 57 years) This conflict between the health system and the healers providing community-based support will need to be addressed to improve the effectiveness of the intervention (Table 1).

Table 1

Adoptation Table

$\begin{array}{lll}\begin{array}{l}\text { Type of } \\ \text { Adaptations } \\ \text { made }\end{array} & \begin{array}{l}\text { Adaptation } \\ \text { type }\end{array} & \begin{array}{l}\text { Reasons for } \\ \text { Adaptation }\end{array} \\ \begin{array}{lll}\text { Added new } \\ \text { activities }\end{array} & \begin{array}{l}\text { Added other } \\ \text { activities } \\ \text { beyond } \\ \text { core } \\ \text { elements }\end{array} & \begin{array}{l}\text { People living with HIV } \\ \text { needed additional } \\ \text { support to remain } \\ \text { adherent to } \\ \text { medication }\end{array}\end{array}$
Adaptations made during
implementation
No. of providers

(Out of

26)

Provision of directly observed therapy to people suspected of not adhering to treatment

Daily or weekly home visits, determined by healer

Provision of food to those who could not afford to purchase it (typically those abandoned by family members)

10
8

Health care workers refused recognize the role of healers

Engagement of clinical leaders

12 to direct clinicians to respect healer support

Changed to educational messages
Need for program messages to address local context
Messaging about drinking two cups of water with each dose of medication if patient does not have access to food
Customized

for problem with food scarcity

\section{Discussion}


This study reports the findings from focus group data from 19 traditional healers and individual interviews with 23 patients describing their experiences delivering or receiving community-based support services in rural Mozambique. Traditional healers described their experiences delivering an evidencebased practice (an adherence support worker for people living with HIV) in an extremely poor, rural community. Both traditional healers and patients reported that education and counseling services, including support in the disclosure of a patient's HIV status, were delivered with fidelity. Patients reported the positive impact of counseling on their ability to see a future with the disease. Given the association of HIV with impending death ${ }^{60}$ and high stigma ${ }^{61-64}$ in the region, patients felt overwhelmed after receiving their diagnosis. Healer counseling provided the reassurance that side effects would go away after a short time and offered strategies (e.g. drink two cups of water with pills) to improve adherence to ART. While a counselor could have provided this information, participants reported the value of receiving this information from a healer - someone who is trusted, familiar, and accessible.

Disclosure of a person's HIV status, particularly for women, can be a stressful and dangerous event. ${ }^{65-69}$ During the adaption of the evidence-based intervention, participants noted the importance of couplecounseling training to facilitate safe disclosure. Eight of our healers described ways in which they provided disclosure assistance, most frequently with women. Most of these disclosure events were done carefully, with consent of the PLHIV, and in a private location, resulting in family support for the uptake of HIV medication. Other attempts at disclosure, however, were less successful, and led to familial abandonment and disruptions in treatment adherence. There was no evidence that healer-supported disclosures were incorrectly supported; but the challenges experienced by some PLHIV highlight the importance of community-based services for those who need housing, financial or additional psychosocial support. $^{70,71}$

One of the core elements of the program, advocating for patient needs at the health facility, was poorly implemented. Healers were trained in identifying factors to bring to the attention of a health care provider and health care providers at the clinic were included throughout the creation of the program to increase acceptability towards the intervention. ${ }^{42}$ Despite these efforts, sociocultural norms, including dismissive attitudes towards healers from health care providers, made advocacy difficult. Patients' interviews highlighted the challenges they encountered with disrespectful health care providers and poorly implemented clinical services. While the intervention was designed, at least in part, to overcome these documented issues with care delivery, ${ }^{72}$ our strategies were largely unsuccessful. Individuals that challenge the authority of a physician frequently are labeled "difficult" and fear losing support from their physician, suggesting the need for novel efforts to overcome this issue in future iterations. ${ }^{73}$

Several healers reported adopting DOT therapy for patients suspected of poor adherence. While not part of the original program, it is commonly employed in the region for TB medication, ${ }^{74,75}$ so people in the region are familiar with the protocol. We did not expect healers to employ this strategy for two reasons: 1 ) we never discussed it during the training program and 2) DOT is extremely time consuming and we did not provide compensation commensurate with the effort this intervention required. If DOT is integrated 
into this healer adherence support worker intervention, it must be systematically implemented by all healers.

\section{Limitations}

This study has several limitations. First, this study was implemented in a rural area of central Mozambique. Experiences and attitudes may not be generalizable to more urban communities. Second, despite our efforts, we did not interview patients who had abandoned treatment altogether. Thus, our findings exclude perspectives from patients who abandoned care. These patients may have experienced greater challenges with disclosure or a need for additional counseling than those who completed the interviews. Importantly, all interviews were conducted after the 12-month study period; it is possible that patient and healer perspectives may have been different had interviews been conducted earlier, when ARTrelated issues may have been more salient.

\section{Conclusions}

Traditional healers were able to successfully implement most components of the adherence support worker intervention and adapted evidence-based practices (e.g. DOTS) from TB services to support PLHIV struggling to take their medication. While healers championed for their patients, health care workers were frequently unwilling to listen to their requests for assistance, with a negative impact on the clinical services provided to PLHIV. Future iterations of this program will need to secure buy-in from health care providers to fully implement the program as designed.

\section{Abbreviations}

ART: Antiretroviral Therapy

DOT: Directly observed therapy

IRB: Institutional Review Board

MISAU: Mozambique Ministry of Health

PLHIV: People living with HIV

TB: Tuberculosis

\section{Declarations}

\section{Ethical Approval and Consent to participate}

This study was approved by the Vanderbilt University Institutional Review Board (IRB\# 150217) and the Zambézia Committee of Bioethics for Health (IRB\# 03/DIBS-Z/15). All participants provided written 


\section{Consent for publication}

Not applicable

\section{Availability of data and materials}

Data is available from the corresponding author on reasonable request.

\section{Competing interests}

None

\section{Funding}

This study was funded by K01MH107255(Audet)

\section{Authors' contributions}

CMA and JS conceived and designed the study. JS and CMA participated in the data collection. CMA and MPP participated in the data analysis and wrote the first draft of the manuscript. All authors reviewed and revised the manuscript and read and approved the final manuscript.

\section{Acknowledgements}

We would like to thank Judite Laimo and Noemia Azevedo for their interviewing prowess.

\section{Author information}

Department of Health Policy, Vanderbilt University School of Medicine, Nashville, Tennessee, USA

Carolyn M. Audet

Institute for Global Health, Vanderbilt University School of Medicine, Nashville, Tennessee, USA

Carolyn M. Audet and Mariah Pettapiece-Phillips

Friends in Global Health, Quelimane, Mozambique 
Jose Salato

\section{References}

1. Desai M, Field N, Grant R, McCormack S. Recent advances in pre-exposure prophylaxis for HIV. BMJ (Clinical research ed). 2017;359:j5011-j5011.

2. McCormack S, Dunn DT, Desai M, et al. Pre-exposure prophylaxis to prevent the acquisition of HIV-1 infection (PROUD): effectiveness results from the pilot phase of a pragmatic open-label randomised trial. Lancet. 2016;387(10013):53-60.

3. Cohen MS, Chen YQ, McCauley M, et al. Antiretroviral Therapy for the Prevention of HIV-1 Transmission. The New England journal of medicine. 2016;375(9):830-839.

4. Palella FJ, Jr., Delaney KM, Moorman AC, et al. Declining morbidity and mortality among patients with advanced human immunodeficiency virus infection. HIV Outpatient Study Investigators. The New England journal of medicine. 1998;338(13):853-860.

5. Pasternak AO, Grijsen ML, Wit FW, et al. Cell-associated HIV-1 RNA predicts viral rebound and disease progression after discontinuation of temporary early ART. JCI Insight. 2020;5(6):e134196.

6. Colby DJ, Trautmann L, Pinyakorn S, et al. Rapid HIV RNA rebound after antiretroviral treatment interruption in persons durably suppressed in Fiebig I acute HIV infection. Nat Med. 2018;24(7):923926.

7. Ahonkhai AA, Adeola J, Banigbe B, et al. Impact of Unplanned Care Interruption on CD4 Response Early After ART Initiation in a Nigerian Cohort. Journal of the International Association of Providers of AIDS Care. 2017;16(1):98-104.

8. Mendez-Lopez A, McKee M, Stuckler D, et al. Population uptake and effectiveness of test-and-treat antiretroviral therapy guidelines for preventing the global spread of HIV: an ecological cross-national analysis. HIV medicine. 2019;20(8):501-512.

9. World Health Organization. Treat all: policy adoption and implementation status in countries. 2019.

10. Brazier E, Maruri F, Duda SN, et al. Implementation of "Treat-all" at adult HIV care and treatment sites in the Global leDEA Consortium: results from the Site Assessment Survey. Journal of the International AIDS Society. 2019;22(7):e25331.

11. Merten S, Kenter E, McKenzie O, Musheke M, Ntalasha H, Martin-Hilber A. Patient-reported barriers and drivers of adherence to antiretrovirals in sub-Saharan Africa: a meta-ethnography. Tropical medicine \& international health : TM \& IH. 2010;15 Suppl 1:16-33.

12. Croome N, Ahluwalia M, Hughes LD, Abas M. Patient-reported barriers and facilitators to antiretroviral adherence in sub-Saharan Africa. AIDS (London, England). 2017;31(7):995-1007.

13. Bezabhe WM, Chalmers L, Bereznicki LR, Peterson GM, Bimirew MA, Kassie DM. Barriers and facilitators of adherence to antiretroviral drug therapy and retention in care among adult HIV-positive patients: a qualitative study from Ethiopia. PloS one. 2014;9(5):e97353. 
14. Denison JA, Koole O, Tsui S, et al. Incomplete adherence among treatment-experienced adults on antiretroviral therapy in Tanzania, Uganda and Zambia. AIDS (London, England). 2015;29(3):361371.

15. Ammon N, Mason S, Corkery JM. Factors impacting antiretroviral therapy adherence among human immunodeficiency virus-positive adolescents in Sub-Saharan Africa: a systematic review. Public health. 2018;157:20-31.

16. Katz IT, Ryu AE, Onuegbu AG, et al. Impact of HIV-related stigma on treatment adherence: systematic review and meta-synthesis. J Int AIDS Soc. 2013;16(3 Suppl 2):18640.

17. Musumari PM, Feldman MD, Techasrivichien T, Wouters E, Ono-Kihara M, Kihara M. "If I have nothing to eat, I get angry and push the pills bottle away from me": A qualitative study of patient determinants of adherence to antiretroviral therapy in the Democratic Republic of Congo. AIDS care. 2013;25(10):1271-1277.

18. Gourlay A, Birdthistle I, Mburu G, lorpenda K, Wringe A. Barriers and facilitating factors to the uptake of antiretroviral drugs for prevention of mother-to-child transmission of HIV in sub-Saharan Africa: a systematic review. J Int AIDS Soc. 2013;16:18588.

19. Fuente-Soro L, Iniesta C, López-Varela E, et al. Tipping the balance towards long-term retention in the HIV care cascade: A mixed methods study in southern Mozambique. PloS one. 2019;14(9):e0222028e0222028.

20. Calder $\mathrm{CL}, \mathrm{O}$ 'Hara H, Tabatabai M, et al. Adherence to Combination Antiretroviral Therapy among Pregnant Women Enrolled in a HIV Prevention Program in Rural North-central Nigeria. Int J MCH AIDS. 2020;9(1):81-92.

21. Groh K, Audet CM, Baptista A, et al. Barriers to antiretroviral therapy adherence in rural Mozambique. BMC Public Health. 2011;11:650.

22. Schwitters A, Lederer P, Zilversmit $L$, et al. Barriers to health care in rural Mozambique: a rapid ethnographic assessment of planned mobile health clinics for ART. Glob Health Sci Pract. 2015;3(1):109-116.

23. MacCarthy S, Saya U, Samba C, Birungi J, Okoboi S, Linnemayr S. "How am I going to live?": exploring barriers to ART adherence among adolescents and young adults living with HIV in Uganda. BMC Public Health. 2018;18(1):1158.

24. Cornelius LJ, Erekaha SC, Okundaye JN, Sam-Agudu NA. A Socio-Ecological Examination of Treatment Access, Uptake and Adherence Issues Encountered By HIV-Positive Women in Rural NorthCentral Nigeria. Journal of evidence-informed social work. 2018;15(1):38-51.

25. Koole O, Denison JA, Menten J, et al. Reasons for Missing Antiretroviral Therapy: Results from a Multi-Country Study in Tanzania, Uganda, and Zambia. PloS one. 2016;11(1):e0147309-e0147309.

26. Madeghe BA, Kimani VN, Vander Stoep A, Nicodimos S, Kumar M. Postpartum depression and infant feeding practices in a low income urban settlement in Nairobi-Kenya. BMC Res Notes. 2016;9(1):506.

27. Rasschaert $F$, Decroo T, Remartinez D, et al. Adapting a community-based ART delivery model to the patients' needs: a mixed methods research in Tete, Mozambique. BMC Public Health. 2014;14:364. 
28. Fox MP, Pascoe S, Huber AN, et al. Adherence clubs and decentralized medication delivery to support patient retention and sustained viral suppression in care: Results from a cluster-randomized evaluation of differentiated ART delivery models in South Africa. PLoS medicine. 2019;16(7):e1002874.

29. Bock P, Gunst C, Maschilla L, et al. Retention in care and factors critical for effectively implementing antiretroviral adherence clubs in a rural district in South Africa. Journal of the International AIDS Society. 2019;22(10):e25396-e25396.

30. Filimão DBC, Moon TD, Senise JF, Diaz RS, Sidat M, Castelo A. Individual factors associated with time to non-adherence to ART pick-up within HIV care and treatment services in three health facilities of Zambézia Province, Mozambique. PloS one. 2019;14(3):e0213804.

31. Jobarteh K, Shiraishi RW, Malimane I, et al. Community ART Support Groups in Mozambique: The Potential of Patients as Partners in Care. PloS one. 2016;11(12):e0166444.

32. Decroo T, Telfer B, Dores CD, et al. Effect of Community ART Groups on retention-in-care among patients on ART in Tete Province, Mozambique: a cohort study. BMJ open. 2017;7(8):e016800.

33. Wringe A, Cawley C, Szumilin E, et al. Retention in care among clinically stable antiretroviral therapy patients following a six-monthly clinical consultation schedule: findings from a cohort study in rural Malawi. J Int AIDS Soc. 2018;21(11):e25207.

34. Wilkinson L, Grimsrud A, Cassidy T, et al. A cluster randomized controlled trial of extending ART refill intervals to six-monthly for anti-retroviral adherence clubs. BMC infectious diseases. 2019;19(1):674.

35. Mottiar S, Lodge T. The role of community health workers in supporting South Africa's HIV/ AIDS treatment programme. African journal of AIDS research : AJAR. 2018;17(1):54-61.

36. Busza J, Dauya E, Bandason T, et al. The role of community health workers in improving HIV treatment outcomes in children: lessons learned from the ZENITH trial in Zimbabwe. Health policy and planning. 2018;33(3):328-334.

37. Källander K, Tibenderana JK, Akpogheneta OJ, et al. Mobile health (mHealth) approaches and lessons for increased performance and retention of community health workers in low- and middleincome countries: a review. Journal of medical Internet research. 2013;15(1):e17.

38. Simon S, Chu K, Frieden M, et al. An integrated approach of community health worker support for HIV/AIDS and TB care in Angónia district, Mozambique. BMC International Health and Human Rights. 2009;9(1):13.

39. Mwai GW, Mburu G, Torpey K, Frost P, Ford N, Seeley J. Role and outcomes of community health workers in HIV care in sub-Saharan Africa: a systematic review. J Int AIDS Soc. 2013;16:18586.

40. Ministry of Health Mozambique (MISAU). Programa de Revitalização dos Agentes Polivalentes Elementares. In:2010.

41. Wanyama JN, Tsui S, Kwok C, et al. Persons living with HIV infection on antiretroviral therapy also consulting traditional healers: a study in three African countries. International journal of STD \& AIDS. 2017;28(10):1018-1027. 
42. Audet CM, Salato J, Vermund SH, Amico KR. Adapting an adherence support workers intervention: engaging traditional healers as adherence partners for persons enrolled in HIV care and treatment in rural Mozambique. Implementation science : IS. 2017;12(1):50-50.

43. Audet CM, Salato J, Vermund SH, Amico KR. Adapting an adherence support workers intervention: engaging traditional healers as adherence partners for persons enrolled in HIV care and treatment in rural Mozambique. Implementation science : IS. 2017;12(1):50.

44. Audet CM, Blevins M, Moon TD, et al. HIV/AIDS-Related Attitudes and Practices Among Traditional Healers in Zambezia Province, Mozambique. Journal of Alternative and Complementary Medince. 2012;18(12):1-9.

45. Audet CM, Salato J, Blevins M, Amsalem D, Vermund SH, Gaspar F. Educational Intervention Increased Referrals to Allopathic Care by Traditional Healers in Three High HIV-Prevalence Rural Districts in Mozambique. PloS one. 2013;8(8):e70326.

46. Breitenstein SM, Gross D, Garvey CA, Hill C, Fogg L, Resnick B. Implementation fidelity in communitybased interventions. Res Nurs Health. 2010;33(2):164-173.

47. Instituto Nacional de Estatistica. Projecções da População 2017 - 2050. 2017; http://www.ine.gov.mz/iv-rgph-2017/projeccoes-da-populacao-2017-2050.

48. Instituto Nacional de Estatistica. 2019; http://www.ine.gov.mz/iv-rgph-2017/mocambique/.

49. UNAIDS. Country: Mozambique 2019;

https://www.unaids.org/en/regionscountries/countries/mozambique Accessed October 7, 2019, 2019.

50. Kharsany AB, Karim QA. HIV Infection and AIDS in Sub-Saharan Africa: Current Status, Challenges and Opportunities. The open AIDS journal. 2016;10:34-48.

51. Ministry of Health Mozambique (MISAU). https://www.state.gov/wpcontent/uploads/2019/09/Mozambique_COP19-Strategic-Directional-Summary_public.pdf. In:2019.

52. Ministerio da Saude (MISAU). Relatório Anual 2019 Relatório Anual das Actividades Relacionadas ao HIV/SIDA. In. Maputo2019.

53. Shepherd BE, Blevins M, Vaz LM, et al. Impact of definitions of loss to follow-up on estimates of retention, disease progression, and mortality: application to an HIV program in Mozambique. American journal of epidemiology. 2013;178(5):819-828.

54. Wingood GM, DiClemente RJ. The ADAPT-ITT model: a novel method of adapting evidence-based HIV Interventions. Journal of acquired immune deficiency syndromes (1999). 2008;47 Suppl 1:S4046.

55. Tong A, Sainsbury P, Craig J. Consolidated criteria for reporting qualitative research (COREQ): a 32item checklist for interviews and focus groups. International Journal for Quality in Health Care. 2007;19(6):349-357.

56. Braun V, Clarke V. Using thematic analysis in psychology. Qualitative Research in Psychology. 2006;3(2):77-101. 
57. Amico KR. A situated-Information Motivation Behavioral Skills Model of Care Initiation and Maintenance (sIMB-CIM): an IMB model based approach to understanding and intervening in engagement in care for chronic medical conditions. J Health Psychol. 2011;16(7):1071-1081.

58. Fisher CM. Are Information, Motivation, and Behavioral Skills Linked with HIV-Related Sexual Risk among Young Men Who Have Sex with Men? J HIV AIDS Soc Serv. 2011;10(1):5-21.

59. Fisher JD, Amico KR, Fisher WA, Harman JJ. The information-motivation-behavioral skills model of antiretroviral adherence and its applications. Curr HIV/AIDS Rep. 2008;5(4):193-203.

60. Adams AK, Zamberia AM. "I will take ARVs once my body deteriorates": an analysis of Swazi men's perceptions and acceptability of Test and Start. African journal of AIDS research : AJAR. 2017;16(4):295-303.

61. Ha JH, Van Lith LM, Mallalieu EC, et al. Gendered relationship between HIV stigma and HIV testing among men and women in Mozambique: a cross-sectional study to inform a stigma reduction and male-targeted HIV testing intervention. BMJ open. 2019;9(10):e029748.

62. Carrasco MA, Arias R, Figueroa ME. The multidimensional nature of HIV stigma: evidence from Mozambique. African journal of AIDS research : AJAR. 2017;16(1):11-18.

63. Andrade RG, Iriart JAB. [Stigma and discrimination: the experiences of HIV-positive women in poor neighborhoods of Maputo, Mozambique]. Cad Saude Publica. 2015;31:565-574.

64. Mukolo A, Blevins M, Victor B, Vaz LME, Sidat M, Vergara A. Correlates of Social Exclusion and Negative Labeling and Devaluation of People Living with HIV/AIDS in Rural Settings: Evidence from a General Household Survey in Zambézia Province, Mozambique. PloS one. 2013;8(10):e75744.

65. Naigino R, Makumbi F, Mukose A, et al. HIV status disclosure and associated outcomes among pregnant women enrolled in antiretroviral therapy in Uganda: a mixed methods study. Reproductive health. 2017;14(1):107-107.

66. Rujumba J, Neema S, Byamugisha R, Tylleskär T, Tumwine JK, Heggenhougen HK. "Telling my husband I have HIV is too heavy to come out of my mouth": pregnant women's disclosure experiences and support needs following antenatal HIV testing in eastern Uganda. J Int AIDS Soc. 2012;15(2):17429.

67. Maeri I, El Ayadi A, Getahun M, et al. "How can I tell?" Consequences of HIV status disclosure among couples in eastern African communities in the context of an ongoing HIV "test-and-treat" trial. AIDS care. 2016;28 Suppl 3(Suppl 3):59-66.

68. Bott S, Obermeyer CM. The social and gender context of HIV disclosure in sub-Saharan Africa: a review of policies and practices. Sahara j. 2013;10 Suppl 1(0 1):S5-16.

69. Kennedy CE, Haberlen S, Amin A, Baggaley R, Narasimhan M. Safer disclosure of HIV serostatus for women living with HIV who experience or fear violence: a systematic review. Journal of the International AIDS Society. 2015;18(Suppl 5):20292-20292.

70. Audet CM, Burlison J, Moon TD, Sidat M, Vergara AE, Vermund SH. Sociocultural and epidemiological aspects of HIV/AIDS in Mozambique. BMC Int Health Hum Rights. 2010;10:15. 
71. Ridgeway K, Lenzi R, Packer C, et al. 'I married when I was $16 \ldots$ due to poverty, I had no other way': multi-level factors influencing HIV-related sexual risk behaviours among adolescent girls in Zambézia, Mozambique. Culture, health \& sexuality. 2020:1-17.

72. Audet CM, Groh KE, Moon TD, Vermund SH, Sidat M. Poor quality health services and lack of program support leads to low uptake of HIV testing in rural Mozambique. Journal of African AIDS Research. 2012;4(327-335).

73. Frosch DL, May SG, Rendle KAS, Tietbohl C, Elwyn G. Authoritarian Physicians And Patients' Fear Of Being Labeled 'Difficult' Among Key Obstacles To Shared Decision Making. Health Affairs. 2012;31(5):1030-1038.

74. Wikman-Jorgensen PE, Morales-Cartagena A, Llenas-García J, et al. Implementation challenges of a TB programme in rural northern mozambique: evaluation of 2012-2013 outcomes. Pathog Glob Health. 2015;109(5):221-227.

75. García-Basteiro AL, Respeito D, Augusto OJ, et al. Poor tuberculosis treatment outcomes in Southern Mozambique (2011-2012). BMC infectious diseases. 2016;16:214-214.

\section{Supplementary Files}

This is a list of supplementary files associated with this preprint. Click to download.

- 32qualchecklist.docx 